\title{
Protection Against Common Bean Rust Conferred by a Gene-Silencing Method
}

\author{
Bret Cooper and Kimberly B. Campbell
}

Soybean Genomics and Improvement Laboratory, United States Department of Agriculture-Agricultural Research Service, Beltsville, MD 20705.

Accepted for publication 19 April 2017.

\begin{abstract}
Rust disease of the dry bean plant, Phaseolus vulgaris, is caused by the fungus Uromyces appendiculatus. The fungus acquires its nutrients and energy from bean leaves using a specialized cell structure, the haustorium, through which it secretes effector proteins that contribute to pathogenicity by defeating the plant immune system. Candidate effectors have been identified by DNA sequencing and motif analysis, and some candidates have been observed in infected leaves by mass spectrometry. To assess their roles in pathogenicity, we have inserted small fragments of genes for five candidates into Bean pod mottle virus. Plants were infected with recombinant virus and then challenged with $U$. appendiculatus.

Virus-infected plants expressing gene fragments for four of five candidate effectors accumulated lower amounts of rust and had dramatically less rust disease. By contrast, controls that included a fungal gene fragment for a septin protein not expressed in the haustorium died from a synergistic reaction between the virus and the fungus. The results imply that RNA generated in the plant moved across the fungal haustorium to silence effector genes important to fungal pathogenicity. This study shows that four bean rust fungal genes encode pathogenicity determinants and that the expression of fungal RNA in the plant can be an effective method for protecting bean plants from rust.
\end{abstract}

Millions of indigent people in Central America and Africa who practice subsistence agriculture depend on dry beans as a primary source of protein (Petry et al. 2015). Their food security is threatened by Uromyces appendiculatus, an obligate biotrophic fungus that causes rust disease on the common dry bean plant, Phaseolus vulgaris. Bean rust is one of the most devastating bean diseases in the world and can cause defoliation and severe yield loss on susceptible bean plants (Pastor-Corrales et al. 2001). Genetic hypersensitive resistance, the most cost-effective method of control, is conferred by dominant resistance $(R)$ alleles that can be traced to two geographic regions of origin, Andes and Mesoamerica, where distinct bean rust isolates coevolved with their hosts (Pastor-Corrales 2004). Because of this regional evolutionary adaptation, Andean germplasm is a source of resistance to some Mesoamerican rust isolates and vice versa. International efforts are underway to breed new varieties of resistant beans by combining the geographic gene pools (Pastor-Corrales et al. 2001). Rusts, however, historically overcome $R$ genes (Johnson 1961); therefore, alternative modes of control need to be considered and the mechanisms by which rusts infect plants need to be investigated.

The windborne asexual uredospores of Uromyces spp. germinate in dew on leaf surfaces, and the emergent germlings penetrate stomata to enter the leaf apoplast in search of suitable cells to infect (Hoch et al. 1987). Once inside the leaf, the fungal hypha swells to form a haustorium mother cell that degrades a mesophyll cell wall. The mother cell then forms a haustorium to interface with the plant cell membrane (Staples and Hoch 1988). The haustorium serves as a conduit of molecular exchange required to establish fungal biotrophy.

Corresponding author: B. Cooper; E-mail address: bret.cooper@ars.usda.gov

*The $\boldsymbol{e}$-Xtra logo stands for "electronic extra" and indicates that one supplementary data set is published online.

This article is in the public domain and not copyrightable. It may be freely reprinted with customary crediting of the source. The American Phytopathological Society, 2017.
Proteins that enable the fungus to overcome the plant immune system or that program the plant to produce nutrients for the fungus are called effectors. It is likely that many effectors traverse the haustorial membrane (Garnica et al. 2014). There are a few effectors from fungal and oomycete plant pathogens for which the biochemical functions are known (Niks et al. 2015), but only recently have effectors from rust fungi been shown to disrupt immunity in host and surrogate plant systems (De Carvalho et al. 2016; Germain et al. in press; Kunjeti et al. 2016; Liu et al. in press; Qi et al. 2016; Ramachandran et al. 2017). For example, $P p \mathrm{EC} 23$ from the soybean rust fungus likely interacts with a soybean transcription factor to suppress disease resistance (Qi et al. 2016). Meanwhile, there are two characterized Uromyces spp. proteins, RTP1 and a hexose transporter, but their defense suppression roles have yet to be demonstrated (Kemen et al. 2005; Voegele et al. 2001). RTP1 may be a cysteine protease inhibitor or may provide structural support for the haustorium (Kemen et al. 2013; Pretsch et al. 2013) whereas the hexose transporter likely helps the fungus acquire carbohydrate nutrients from its host.

The functional characterization of rust effectors has been slowed by the obligate biotrophic nature of rust fungi. No mutant lines of rust fungi exist, and it is difficult to distinguish between the biochemical functions of factors contributing to biotrophy and pathogenicity because they are intertwined for an obligate biotrophic pathogen. One possible mechanism for testing gene function in haustorium-forming fungi and oomycetes is gene silencing, also known as RNAi (Nunes and Dean 2012). Nowara et al. (2010) proved this concept by using Barley stripe mosaic virus (BSMV) to transiently express RNA fragments of powdery mildew fungus Blumeria graminis 1,3- $\beta$-glucanosyltransferase genes in wheat and by using transformation to stably express RNA hairpin loops of the same in barley. They observed reduced amounts of powdery mildew on the plants. The results implied that the fungus was capable of receiving and processing an RNAmediated gene-silencing signal from the plant. Panwar et al. (2013) subsequently showed that BSMV expressing RNA fragments of general pathogenicity genes of the wheat leaf rust fungus Puccinia triticina also led to a reduction of rust in wheat. 
They observed in the BSMV-infected wheat the presence of smallinterfering RNA (siRNA) for the targeted genes, an indicator of the activation of RNA-silencing pathways. The results from these and other studies have revealed that RNA produced by the plant can move to the fungus, possibly through the haustorium, to activate gene-silencing pathways in the fungus (Yin et al. 2011, 2015). This can compromise fungal gene expression and protein production, resulting in reduced fungal accumulation and pathogenicity. Consequently, plant-mediated gene silencing appears to be a useful method to test the function of fungal genes. At the same time, it also shows promise as a mechanism to protect plants from fungal disease (Cheng et al. 2015; Govindarajulu et al. 2015; Hu et al. 2015; Koch et al. 2013).

We are interested in characterizing the effectors of $U$. appendiculatus to understand their roles in pathology, and we are interested in improving bean cultivars and broadening their resistance to rust. To identify $U$. appendiculatus candidate effectors, we sequenced cDNA from $U$. appendiculatus germlings, purified haustoria, and infected bean leaves (Cooper et al. 2007; Link et al. 2014; Puthoff et al. 2008). Candidate effector genes were selected for the presence of sequences that could target their proteins for secretion from the fungus. Many of the candidates resembled genes found only in other rust fungi, and this implied that they were important to rust biology. We then used mass spectrometry to verify that 58 candidate effector genes were expressed as proteins in infected bean leaves (Cooper et al. 2016). Now, to verify whether these candidate effectors are important for fungal pathogenicity, we have expressed a small portion of their genes in plants using Bean pod mottle virus (BPMV), a virus that can initiate gene silencing (Zhang et al. 2013). We then challenged the virus-infected plants with $U$. appendiculatus. Here, we report that the common bean rust fungus genes are pathogenicity determinants and that host-induced RNA silencing can protect bean plants from rust infection.

\section{MATERIALS AND METHODS}

DNA cloning. DNA sequences for $U$. appendiculatus candidate effector genes 14349PIG15plike (contig14349), 05723chit (contig05732), 15794unkn (contig15794), 05026fam26 (contig05026), 02CFH03sep (Hyp_02C_F_H03), and 05556asppep (contig05556) were previously described (Cooper et al. 2007; Link et al. 2014). Overlapping 80-mer oligonucleotides were used to synthesize a 258-bp DNA fragment proximal to the stop codon of each candidate gene (Cooper 2014; Cooper et al. 2013). BLAST was used to verify that the fragments did not have homology to DNA sequences in the Phaseolus vulgaris genome (Schmutz et al. 2014). The fragments were amplified with primers that contained unique KpnI and BamHI restriction endonuclease sites and that maintained the translational reading frame of the BPMV RNA2 polyprotein (Table 1). Enzymatically digested polymerase chain reaction (PCR) products were inserted in sense orientation between the KpnI and BamHI restriction sites of pIAD35, which encodes the second genomic segment of BPMV (Zhang et al. 2009, 2010). Plasmid inserts were validated by DNA sequencing.

Pathogen inoculation. pBPMV-R1M (encoding genome segment 1 of a BPMV mutant that helps produce more visible mottle symptoms) and engineered pBPMV-R2 constructs were delivered by biolistics using a PDS-1000/He Gene Gun (Bio-Rad) to the primary leaves of 10-day-old P. vulgaris 'Black Valentine' seedlings. pIA1037, expressing the green fluorescent protein from BPMV genome segment 2 (1037), was used as a control. Bombarded plants developed symptoms on the first trifoliate leaf between 10 and 14 days later, at which point the first and second trifoliate leaves were sprayed with a liquid suspension of uredospores of $U$. appendiculatus race 41 (Cooper et al. 2007; Lee et al. 2009). The plants were placed in an $18^{\circ} \mathrm{C}$ dew chamber for $24 \mathrm{~h}$, then moved to a $23^{\circ} \mathrm{C}$ growth room with fluorescent lighting. One virus-free, rust-inoculated plant was kept as an indicator to ensure successful rust infection, which was measured as two to four pustules per square centimeter of leaf surface. Plants were examined for rust symptoms at 10 days after inoculation (DAI). Experiments in which the indicator plant did not develop rust symptoms at $10 \mathrm{DAI}$ or did not display desired infection density were abandoned.

Reverse-transcription PCR. RNA was purified from virusinfected, uredospore-inoculated leaves when rust uredia appeared on indicator plants and controls. To verify that plants were infected with BPMV and that the virus retained the inserted gene fragment specific to each construct, $1 \mathrm{ng}$ of RNA was amplified for 25 cycles using the Fseq primer for each specific rust gene insert, the IAD35CP655R primer specific to BPMV RNA2 cDNA, and the SuperScript III One-Step reverse-transcription (RT)-PCR kit (Table 1). The resulting approximately 1,240-bp products were separated on $1.0 \%$ agarose gels stained with ethidium bromide. To estimate the amount of $U$. appendiculatus present in inoculated leaves, $10 \mathrm{ng}$ of DNase-treated RNA was tested with the QuantiFast Probe RT-PCR Plus kit (Qiagen) in an Mx3000P machine (Stratagene) according to the manufacturers' instructions. Primers and 6-FAM 5' end-labeled probes were designed to specifically amplify DNA 150 bp upstream from the segment of 14349 PIG15plike from which the silencing construct was derived (Table 1). Primers and a probe to detect the expression of the P. vulgaris elongation factor 1a gene were also used (Lee et al. 2009). All reactions were performed in duplicate. A standard curve consisting of serial 1:5 dilutions of total RNA starting with $250 \mathrm{ng}$ was prepared from rust-infected, BPMV-1037-infected plants. RNA amounts from experimental plants were interpolated from standard curves with a correlation coefficient of $95 \%$ or greater. RNA amounts for 14349PIG15plike were normalized to those for $P$. vulgaris elongation factor $1 \mathrm{a}$.

Small RNA sequencing. Black Valentine leaves infected with BPMV-15794unk were harvested at 10 DAI when virus symptoms began to appear. The plants were not inoculated with bean rust. RT-PCR (described above) confirmed virus infection and that the insert was retained. Small RNA were purified from the leaves using an miRNeasy purification kit (Qiagen). Small RNA were captured by $5^{\prime}$-phosphate groups and sequenced by Genewiz with an Illumina HiSeq2500, using $1 \times 50$-bp SR configuration (V4 Chemistry), producing 5 million siRNA sequences from 68 million reads.

\section{RESULTS}

In prior studies, we identified 58 U. appendiculatus effector protein candidates in rust-infected bean (Cooper et al. 2016; Link et al. 2014). Among these, 24 appeared to uniquely accumulate in infected bean leaves, while the others were found in both infected bean leaves and in germinated $U$. appendiculatus uredospores (germlings). These findings implied that the 24 proteins with specific accumulation in leaves, as opposed to germlings, could be secreted by a haustorium, the fungal cell structure that interfaces the plant cell during fungal biotrophy. Therefore, we initially chose to focus on these effector candidates found in infected plants and not germlings. Because $U$. appendiculatus expresses DICER and $A G O$ genes needed to process siRNA (Cooper et al. 2007; Huang et al. 2016; Link et al. 2014) during infection, we hypothesized that we could use BPMV to express candidate effector RNA in the leaf and induce an RNA signal that could be transmitted to and processed in the haustorium, where effector gene expression and effector protein accumulation could be inhibited by RNAi. We predicted that this would lead to reduced fungal pathogenicity and growth (the two are tied together for an obligate biotroph).

Two candidates we first chose to study were 14349PIG15plike, a trehalose phosphatase family protein with $35 \%$ identity to $U$. viciaefabae PIG15, and 15794unkn, a protein of unknown function with 43\% identity to PSTG_04761 from Puccinia striiformis f. sp. tritici 
(Cooper et al. 2016). These candidate genes were first isolated from a haustorium-specific library and their proteins were among the most abundant candidate effectors found in infected leaves (Cooper et al. 2016; Link et al. 2014). Small DNA fragments of the 3 ' ends of the open reading frames for their genes were synthesized from oligonucleotides and inserted into a DNA plasmid of BPMV RNA2. As a control, we also tested 1037, a BPMV RNA2 that expresses the green fluorescent protein (as opposed to a gene fragment targeted for silencing). DNA plasmids for BPMV RNA1 and RNA2 were cobombarded onto Phaseolus vulgaris seedlings. 35S promoters drove the expression of BPMV RNA, and the virus propagated in the leaves and moved systemically as the plants developed. We confirmed by RT-PCR that the viruses retained the inserted gene fragments as they spread through the plants.

Virus-infected plants were then challenged with $U$. appendiculatus and monitored for rust pustules (uredia), the signs of rust infection. On many plants infected with BPMV-1037, the control virus, we observed rust pustules at $10 \mathrm{DAI}$ (Fig. 1A). By and large, the BPMV1037- and rust-infected plants had pustules covering the surfaces of the leaves. Quantitative RT-PCR analysis using primers that targeted a distinct region of 14349PIG15plike confirmed the accumulation of rust RNA in BPMV-1037- and rust-infected plants (Fig. 2). In addition to rust pustules, we observed a synergistic effect in some BPMV-1037- and rust-infected plants, manifested as a spreading leaf necrosis that led to leaf death and drop for many controls (Figs. 1B and E and 2). Consequently, it was not possible in all cases to extract RNA to test for fungal accumulation by RT-PCR (Fig. 2). Nevertheless, when leaves survived, ample amounts of fungal RNA were detected. Occasionally, however, smaller amounts of fungal RNA were detected on BPMV-1037-infected leaves, but we attributed this to the synergism that possibly limited fungal spread. Altogether, it was apparent that nearly all plants doubly infected with BPMV-1037 and U. appendiculatus suffered from the diseases. Synergistic effects between rust and virus infections have been previously documented (Yarwood 1951).

By contrast, plants infected with BPMV expressing the gene fragments for 14349PIG15plike and 15794unkn developed few rust pustules after being challenged with $U$. appendiculatus (Fig. $1 \mathrm{C}$ and D). Where occasional pustules did appear, it seemed that the leaf area had mild virus symptoms. Leaves infected with mosaic and mottle viruses can have green islands that are free of virus (Suzuki et al. 1989), and this might explain why parts of leaves with mild virus symptoms had one or two rust pustules. Variability in viral transgene expression also might have led to incomplete silencing. Such variability is expected and inherent to this well-established BPMV system and has been observed in other viral systems, too (Yin et al. 2015; Zhang et al. 2013). Nevertheless, the leaves appeared to be mostly free of fungal infection compared with controls. More notable was that none of the leaves infected with BPMV-14349PIG15plike and BPMV-15794unkn exhibited a

TABLE 1. Oligonucleotides used in this study

Name $^{\mathrm{a}}$

14349PIG15plike $1 \mathrm{~F}$ 14349PIG15plike 2R 14349PIG15plike 3F 14349PIG15plike 4R 14349PIG15plike Fseq 14349PIG15plike Rseq 14349PIG15plike RT-qPCR F

14349PIG15plike RT-qPCR R

14349PIG15plike RT-qPCR T 05732chit 1F 05732chit 2R 05732chit 3F 05732chit 4R 05732chit Fseq 05732chit Rseq 15794unkn 1F 15794unkn 2R 15794unkn 3F 15794unkn 4R 15794unkn Fseq 15794unkn Rseq 05026 fam $261 \mathrm{~F}$ 05026 fam 26 2R 05026 fam 26 3F 05026 fam $264 \mathrm{R}$ 05026fam26 Fseq 05026fam 26 Rseq 02CFH03sep $1 \mathrm{~F}$ 02CFH03sep 2R 02CFH03sep 3F 02CFH03sep 4R 02CFH03sep Fseq 02CFH03sep Rseq 05556asppep 1F 05556asppep 2R 05556asppep 3F 05556asppep 4R 05556asppep Fseq 05556asppep Rseq IAD35CP655R
Sequence

TTTGCGGCGCTTACGCACAATGCATGTAACAAGGGAAGACTTGCTTCCACTTTACTTGATAGGTATAGTGGTAATCATTT TGTTGCTCCAGCGCTTCGAACATTGGAACGTCTACTTGAGTATCTCCCAGGGACATGACAAAATGATTACCACTATACCT TTCGAAGCGCTGGAGCAACATTCCAACCCTAGTCGGGGCGCGAAAACATTATCTGTGAGGGTTGGCTCTGCAGATATTTC AAGTAGTGCATTGAAAAATTTGTAAACGTCGTGATGACTTCGTAAACTTGCGTCTGCTGAAATATCTGCAGAGCCAAC aaag GGA TCC CAC GTG TTTGCGGCGCTTACGCACAA

ttg G GTA CCt AAGTAGTGCATTGAAAAATT

GAAAACGTGGAGCGTCAGTA

\section{GCAATGGGTTGGCTAGAAGT}

CCTCACCGTATCTTCGACTCGTTGC

AAAAGCGGTCTCAATGGATACAAACGTTACTTCGATGAGTGCAGTGGTGTCCCCTTCTTAACCAACGGTAAATATTTCAT AAATGTTTCGCTTTCGCGAATTGGGCTTTTGACACTGTGCTTTGTTTGTCATCGTATGAAATGAAATATTTACCGTTGGT TTCGCGAAAGCGAAACATTTAGGCGGAATCTACTTCTTTGACACACAAGGCCCGCTAGATGCCACGGTCCAAGCAGCACG AGTATTGCAGTGATCTCGGGACCTGTATGAAGACGTTCCGCGTGGGTTTATGACTTGGCGTGCTGCTTGGACCGTGGC aaag GGA TCC CAC GTG AAAAGCGGTCTCAATGGATA

ttg G GTA CCt AGTATTGCAGTGATCTCGGG ACTTTTCGTGAATTCTGCGCAATGGATCAAAATGCCGAGCTAATAACCGATCCATCCCTTAGAGCCTCGGTGCAAGAGGT TTGGGAACGACCTCTACTTCCATGGGATGATTCTGGGACGTTTTCACCTGAACTTCCAACACCTCTTGCACCGAGGCTCT GAAGTAGAGGTCGTTCCCAAGAAAGGTGGAAACACTTTTATTGTTAGTCAAATTGATTCTGATGGGCTTGAAAACAAGAT TCTGCTCAATTTGCGCCGTTTGGGTTCACCCCTTGCCATCCAATCGATTAAGTTTTGGATCTTGTTTTCAAGCCCATC aaag GGA TCC CAC GTG ACTTTTCGTGAATTCTGCGC ttg G GTA CCt TCTGCTCAATTTGCGCCGTT

TCTGGTGACTTTGTCAAGCGTATGAAAGAGTTTCACGACACTTTCGCAATCAATGGACGCAAATTCGCTCTTGGAGAAGC GAAGCTATTTGAGTGAGCCAGTCGACACGATCTTTGTAGCTAGCTTCATAATGCAGCCCTGCTTCTCCAAGAGCGAATTT TGGCTCACTCAAATAGCTTCGTCCCGAGATCAGCTTCCTCAACTGGTATACGCCGTTTGGTACAACAGTAAGAAAGAATA TTCCAGCTTGGCCGTCAGAAGGGCTGTTGATAAGCCGTTTCCAGCTAACTTGTAGTTGTATTCTTTCTTACTGTTGTA aaag GGA TCC CAC GTG TCTGGTGACTTTGTCAAGCG

ttg G GTA CCt TTCCAGCTTGGCCGTCAGAA

TATAGAACTCAAACTTTAAGTCAAGGTAATGCTGATCAAATTGGTCAATCCATTCAACCTGAAGATATGGCTACTCAATC AATTCAATTTCTTTCAATTTTTCTTCTTCTTTCCTTAATTGTTCTTCTTTCAACCTGAATGATTGAGTAGCCATATCTTC AAATTGAAAGAAATTGAATTACGTGTGCAACGTGAGATTAGTGAAAAACGACAAGAACTCTTGGTTAAAGAAGAAAGTCT AATGTATTCATCGATAGAAGCAATGGACGCGTGCGCCAAGCGAGCCTCCATGTTTCGAAGACTTTCTTCTTTAACCAA aaag GGA TCC CAC GTG TATAGAACTCAAACTTTAAG

ttg G GTA CCt AATGTATTCATCGATAGAAG

GAGGCTTCCGAAACCTACAAGGCCAATGGTACAGAGTTCCAAATTCGATATGGTTCCGGTAGCTTGGAAGGTGTTATTAG GTGCTTTCGGCAAAATCAACGCCAGGAATGACCAAGTCACCAATTCTGAGCACGTCATTGCTAATAACACCTTCCAAGCT GTTGATTTTGCCGAAAGCACTAAAGAGCCTGGACTTGCGTTTGCTTTTGGCAAGTTTGACGGAATCTTTGGTCTCGGTTA ACGaAcgActttgtTTaAGTaAAgGtgGGGGACGGTGTGAAGGACTGAAATAGTATGGTAACCGAGACCAAAGATTCC aaag GGA TCC CAC GTG GAGGCTTCCGAAACCTACAA ttg G GTA CCt ACGaAcgActttgtTTaAGT TGAGTTGACCAAGCTGTAAGA

${ }^{\mathrm{a}} \mathrm{RT}-\mathrm{qPCR}$ = quantitative reverse-transcription polymerase chain reaction. 
synergistic symptom effect after infection with bean rust. In other words, in contrast to many BPMV-1037- and rust-infected plants, BPMV-14349PIG15plike and BPMV-15794unkn plants challenged with rust survived (Fig. 1E). Quantitative RT-PCR analysis using primers specific to a distinct region of 14349 PIG15plike revealed that most plants inoculated with the silencing viruses and challenged with rust accumulated much less 14349PIG15plike RNA (Fig. 2). Hence, the symptoms and the RT-PCR analysis with respect to the controls revealed that BPMV-14349PIG15plike and BPMV-15794unkn protected the plants from rust infection.

These results imply that the plant produced a silencing signal against the virus and that the signal or RNA migrated across the haustorium, leading to a reduction in fungal gene expression. To determine whether siRNA were potential signals, we inoculated bean with BPMV-15794unkn (but not rust) and sequenced small RNA from leaves at the time we would normally challenge with rust. In all, 1,000 small RNA (approximately 180,000 reads) of 20 to $25 \mathrm{bp}$ and spanning the entire 258-bp length of the inserted 15794unkn fragment were detected (Supplementary Data S1). These data, along with the prior RT-PCR results of reduced RNA expression of 14349 PIG15plike in protected plants (Fig. 2), support our hypothesis that an RNAsilencing signal produced by the plant against a rust gene fragment in BPMV induced RNAi in the rust fungus.

After these successful trials, we examined genes for four other $U$. appendiculatus proteins. A chitinase-like protein, 05732chit, with $47 \%$ identity to a Phakopsora pachyrhizi (soybean rust) homolog, and 05026fam 26, a family 26 glycoside hydrolase with $43 \%$ identity to a $P$. pachyrhizi homolog, were also among the highly abundant proteins found in rust-infected leaves (Cooper et al. 2016). By contrast, 05556asppep, an aspartic peptidase with $77 \%$ identity to a Puccinia striiformis homolog, accumulated to lower levels in plant leaves (Cooper et al. 2016). In addition, 05556asppep was also different than the others because it accumulated in germlings as well as infected leaves (Cooper et al. 2016). Finally, we examined $02 \mathrm{CFH} 03 \mathrm{sep}$, a septin protein that was not observed in infected plants but was found to accumulate to high levels in ungerminated asexual uredospores (Cooper et al. 2007).

Plants infected with BPMV-05732chit were protected from rust similarly to plants infected with BPMV-14349PIG15plike and BPMV-15794unkn (7 of 10 plants) (Fig. 3A) but BPMV-05732chit elicited much stronger virus symptoms on some plants, and this phenotype was associated with leaf stunting and rust accumulation (3 of 10 plants) (Fig. 3B). It is possible that there was off-target silencing that was detrimental to the plant or that the inserted gene fragment produced a read-through protein that increased symptomology in some cases. On the other hand, BPMV-05026fam 26 strongly protected some plants (4 of 10 plants) and weakly protected others (4 of 10 plants) (Fig. 3C and D); synergistic necrosis was observed in just 2 of the 10 plants tested. By contrast, there was no apparent protection conferred by BPMV-05556asppep (0 of 10 plants) (Fig. $3 \mathrm{E}$ ) or BPMV-O2CFH03sep (1 of 10 plants) (Fig. 3F). These plants suffered from rust infection or died from the synergistic reactions.

\section{DISCUSSION}

Few rust fungus effectors have been characterized at a biochemical level. The best described are the avirulence (Avr) proteins from flax rust that elicit hypersensitive resistance in plants with cognate $R$ genes (Barrett et al. 2009; Catanzariti et al. 2006, 2010; Dodds et al. 2004, 2006). Their interactions with $R$ proteins have been characterized in some cases but their primary functions in fungal virulence are not known. Some non-Avr effectors also have been described biochemically but their roles in virulence have been shown in only a few cases. For example, the non-Avr U. fabae RTP1 may support haustorium formation or act as a protease (Kemen et al. 2013; Pretsch et al. 2013). Effector candidates from other rust fungi such as poplar rust have been shown to have distinct subcellular localizations in plant cells, and it is hoped that their cellular

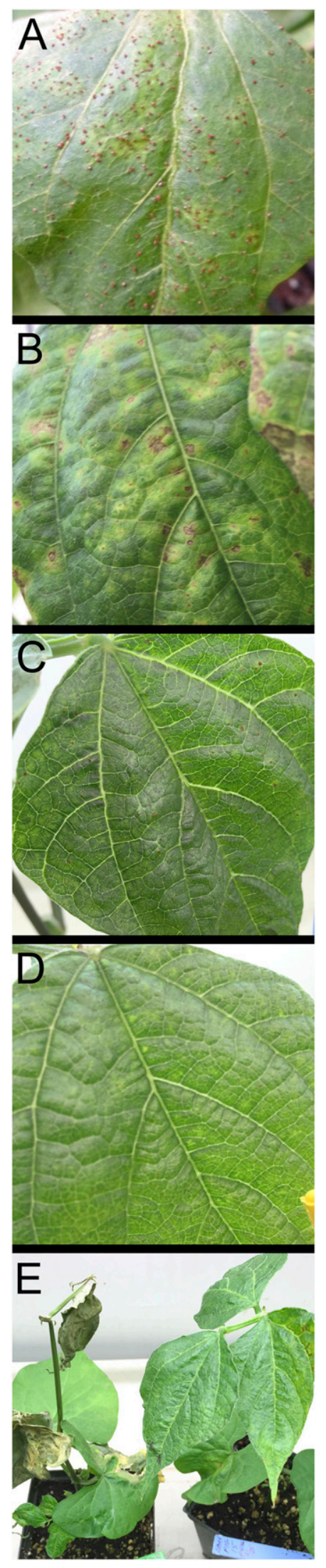

Fig. 1. Phaseolus vulgaris leaves infected with Bean pod mottle virus (BPMV) constructs and subsequently inoculated with Uromyces appendiculatus. A, Fungal uredia (pustules) and spores on a leaf infected with BPMV-1037 (nontargeted silencing control); $\mathbf{B}$, beginnings of synergistic necrosis on a leaf infected with BPMV-1037; C, leaf infected with BPMV-14349PIG15plike showing few pustules; D, leaf infected with BPMV-15794unkn showing few pustules; and E, plants infected with BPMV-1037 (left) and BPMV14349PIG15plike (right). 
activities may betray their roles in pathogenicity or virulence (Germain et al. 2017; Hacquard et al. 2012; Petre et al. 2015). Meanwhile, some soybean rust proteins have been shown to promote virulence but how they function biochemically remains unknown (De Carvalho et al. 2016; Kunjeti et al. 2016; Qi et al. 2016). Hence, it can be said that scientists have made great strides in identifying rust fungal effector proteins but that the quest to characterize the intriguing properties of these effectors goes on.

Our participation in this quest has led to the identification of 58 $U$. appendiculatus candidate effectors in infected common bean leaves (Cooper et al. 2016). Here, we have tested whether five of these candidates are important for pathogenicity by trying to reduce their expressions by BPMV to activate in a bean plant gene-specific silencing signals that could be transmitted back to the fungus. Hypothetically, if the candidate fungal genes are important for pathogenicity, then silencing them could lead to inhibition of pathogenicity and fungal growth. Our results show that the plants infected with BPMV expressing RNA for fragments of four of five candidate effectors developed fewer rust disease symptoms and accumulated less haustorium marker RNA compared with controls (Figs. 1, 2, and 3). In fact, some plants appeared to be free of rust disease, and this distinction was more pronounced compared with some of the controls that died from the synergistic complication of the rust and virus infections.

The results suggest that siRNA derived from BPMV expressing the gene fragments for 14349PIG15plike, 15794unkn, 05732chit, and 05026 fam 26 protected the plants from necrotic death associated
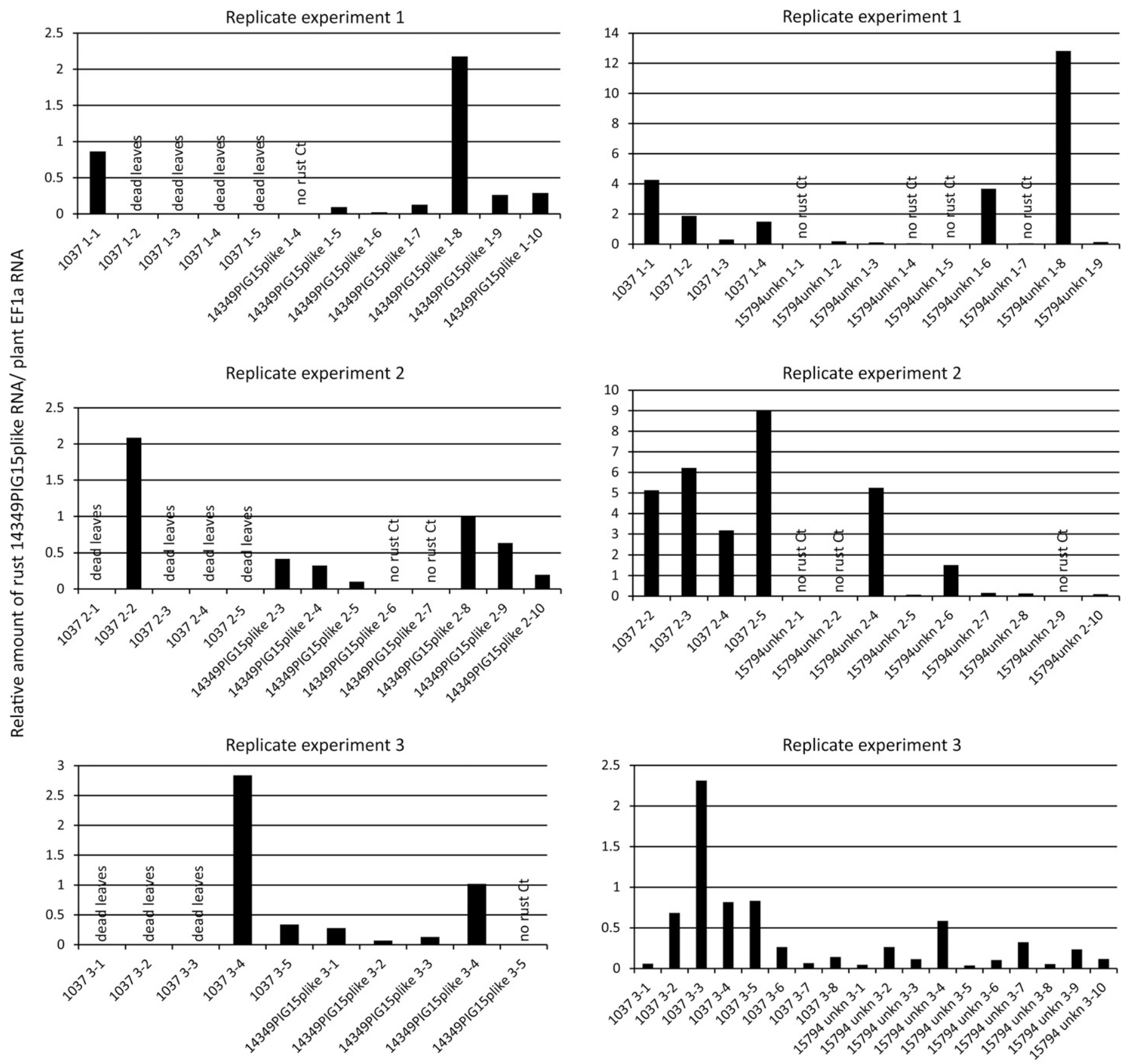

Fig. 2. Relative amounts of Uromyces appendiculatus (rust) 14349PIG15plike RNA with respect to Phaseolus vulgaris (plant) elongation factor 1a (EF1a) RNA in plants infected with Bean pod mottle virus (BPMV)-1037 (control), BPMV-14349PIG15plike (silencing), or BPMV-15794unkn (silencing) and challenged with U. appendiculatus. Three replicate experiments were performed for each silencing construct. Some plants died due to a synergistic reaction between BPMV-1037 and $U$. appendiculatus. Thus, no RNA could be collected. On some plants infected with silencing viruses, there was not enough rust RNA to yield a detectable signal within 40 polymerase chain reaction cycles (no $\mathrm{Ct}$ ). 
with the virus-rust synergistic reaction. Supporting evidence includes BPMV-15794unkn producing siRNA for insert sequence 15794 unkn. We also provide evidence for reduced fungal expression of 14349PIG15plike in bean infected with BPMV14349PIG15plike. This suggests that 14349PIG15plike was specifically silenced, although it is not proof because reduced expression is tied to an overall reduction in fungal biomass for an obligate biotroph. Nevertheless, it has already been shown that, when hair-pin loops for a $\beta$-glucuronidase $(G U S)$ intron were expressed in tobacco and the tobacco was infected with haustoriaforming transgenic Fusarium verticilliodes expressing GUS, the fungus had reduced GUS gene expression (Tinoco et al. 2010). This means that a molecular silencing signal can move from a plant to a fungus. Thus, we hypothesize that the bean plant recognized BPMV as part of its natural defense system and produced siRNA to defend itself from the virus (Baulcombe 2004). Consequently, siRNA were generated for 14349PIG15plike, 15794unkn, 05732chit, and 05026 fam 26 insert sequences and transferred to $U$. appendiculatus to activate gene silencing and reduce the expression of the cognate genes. It is also possible that longer segments of RNA or viral RNA migrated to the fungus (Baulcombe 2015). Either way, the plantproduced RNA triggered gene silencing in the fungus, which resulted in reduced fungal infection and increased plant resistance. These results also demonstrate that 14349PIG15plike, 15794unkn, 05732chit, and 05026fam 26 are important for bean rust fungal pathogenicity and growth. The biochemical mechanisms by which these proteins function remain to be discovered.

On the basis of our mass spectrometry results and other laboratories' genomics results, there are still many more candidate effectors to be tested (Cooper et al. 2016; De Carvalho et al. 2016; Kunjeti et al. 2016). As we investigate, we may discover that the silencing of some effector genes leads to better protection than others, as demonstrated in the Puccinia-BSMV system (Yin et al. 2015). We show here that two of the fungal genes that we interrogated did not provide protection. The aspartic peptidase gene 05556asppep was among the sets of effector candidates identified by bioinformatics but differed from the others in that its protein accumulated in bean rust-infected leaves at lower levels and its expression was not limited to infectious stages (Cooper et al. 2016; Link et al. 2014). The lack of protection implies that 05556asppep is less important than the others for pathogenicity or that it is expressed in plants in a cell structure other than the haustorium and, therefore, is not accessible to siRNA processed in the haustorium. The latter possibility is made more credible with our test with septin, a noneffector with specific accumulation in uredospores but not haustoria (Cooper et al. 2007). Septin functions in cytokinesis; thus, it is possible that septin exists in the uredospore as a remnant of mitosis or a remnant of separation from the uredial primordia (Chen et al. 2016; Muller et al. 1974). Hence, we imagine that the siRNA for septin gene $02 \mathrm{CFH} 03 \mathrm{sep}$, if acquired or produced by the haustorium, do not have an effect on fungal pathogenicity or growth because 02CFH03sep is expressed at a much later stage of development. Of course, it is also possible that the constructs we designed for 05556asppep and 02CFH03sep were, by chance, unsuitable for generating effective gene silencing. At this time, we have a limited understanding of what parts of fungal genes are best suited for inducing silencing through plant-mediated RNAisilencing mechanisms.

In conclusion, our experiments have shown that four bean rust fungal genes promote pathogenicity, and that the inhibition of these proteins can protect bean plants from infection. Nowara et al. (2010), armed with similar results using BSMV to silence powdery mildew genes, made resistant barley by transforming them to express RNA hairpin loops of the fungal gene targets. It should be possible to do the same in dicotyledonous bean and soybean to protect them against rusts. Alternatively, it may be possible to use RNA sprays to incite siRNA pathways that target fungal genes (Dalakouras et al. 2016; Koch et al. 2016). As we pursue these possibilities, we will likely continue to target effector genes or genes critical for a unique component of rust or fungal biology
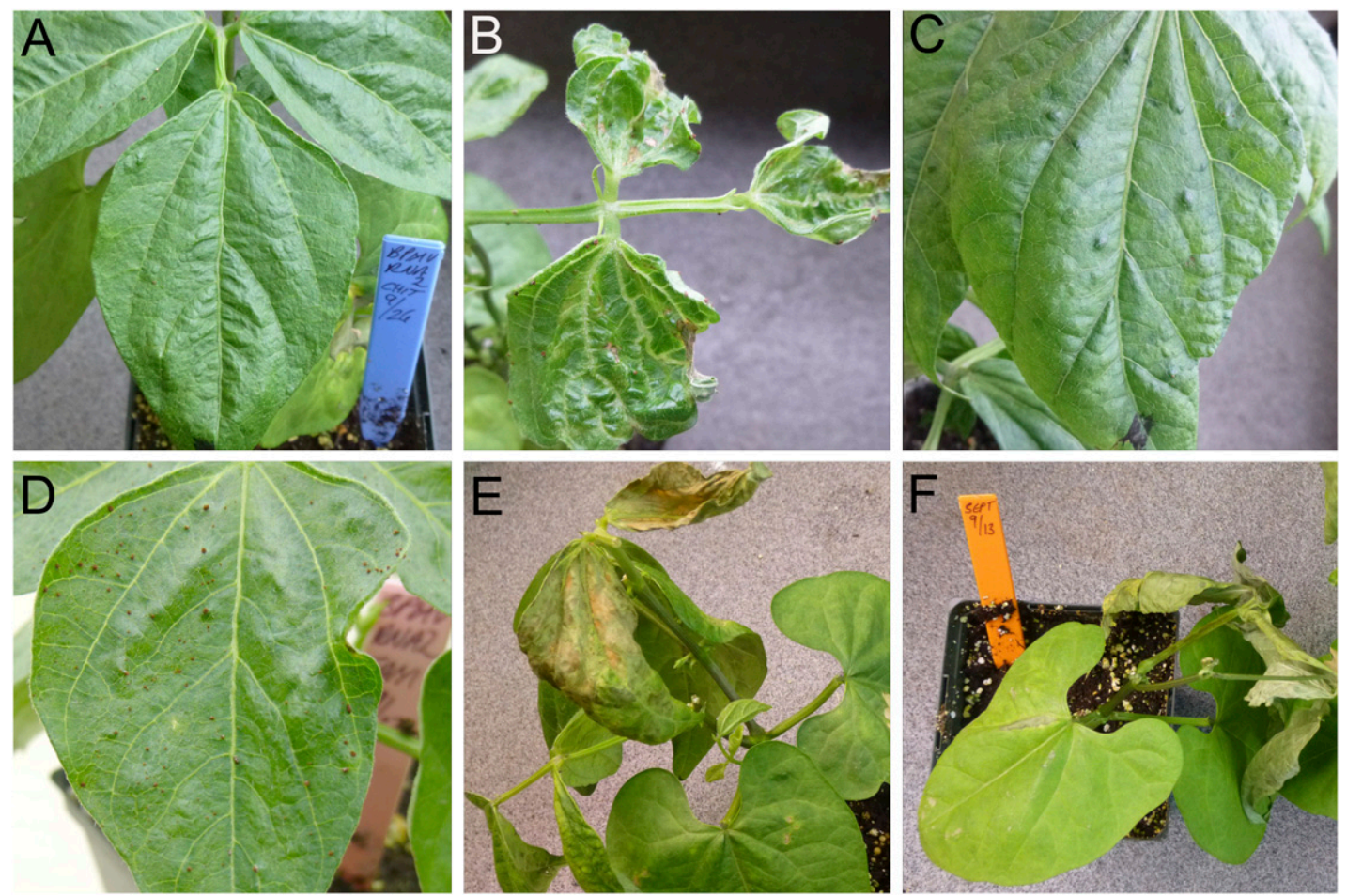

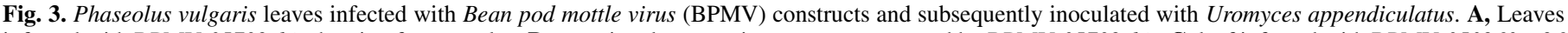

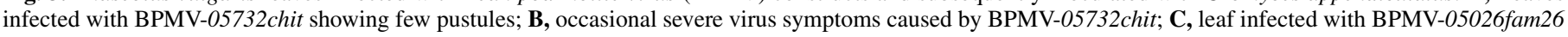

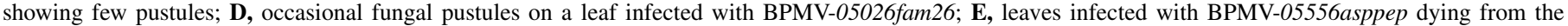
synergistic reaction with rust; and $\mathbf{F}$, leaves infected with BPMV-02CFH03sep dying from the synergistic reaction with rust. 
rather than routine genes for basic biochemistry common to plants and pathogens (Koch et al. 2013). It is possible that strong resistance can be achieved when targeting highly expressed effector proteins because of their importance to pathogenicity and because rust effectors have limited similarity to genes from plants or other organisms. This latter feature may help ensure silencing specificity to rust fungal pathogens. Consequently, we support initiatives to sequence a variety of Uromyces spp. genomes to find genes to which RNAi-mediated resistance mechanisms can be designed. There may be effector genes common to $U$. appendiculatus races of Andean and Mesoamerican descent that can be targeted to achieve broader protection (Yin et al. 2015).

\section{ACKNOWLEDGMENTS}

This research was funded entirely by the United States Department of Agriculture-Agricultural Research Service.

\section{LITERATURE CITED}

Barrett, L. G., Thrall, P. H., Dodds, P. N., van der Merwe, M., Linde, C. C., Lawrence, G. J., and Burdon, J. J. 2009. Diversity and evolution of effector loci in natural populations of the plant pathogen Melampsora lini. Mol. Biol. Evol. 26:2499-2513.

Baulcombe, D. 2004. RNA silencing in plants. Nature 431:356-363.

Baulcombe, D. C. 2015. VIGS, HIGS and FIGS: Small RNA silencing in the interactions of viruses or filamentous organisms with their plant hosts. Curr. Opin. Plant Biol. 26:141-146.

Catanzariti, A. M., Dodds, P. N., Lawrence, G. J., Ayliffe, M. A., and Ellis, J. G. 2006. Haustorially expressed secreted proteins from flax rust are highly enriched for avirulence elicitors. Plant Cell 18:243-256.

Catanzariti, A. M., Dodds, P. N., Ve, T., Kobe, B., Ellis, J. G., and Staskawicz, B. J. 2010. The AvrM effector from flax rust has a structured C-terminal domain and interacts directly with the $\mathrm{M}$ resistance protein. Mol. PlantMicrobe Interact. 23:49-57.

Chen, A., Xie, Q., Lin, Y., Xu, H., Shang, W., Zhang, J., Zhang, D., Zheng, W., Li, G., and Wang, Z. 2016. Septins are involved in nuclear division, morphogenesis and pathogenicity in Fusarium graminearum. Fungal Genet. Biol. 94:79-87.

Cheng, W., Song, X. S., Li, H. P., Cao, L. H., Sun, K., Qiu, X. L., Xu, Y. B., Yang, P., Huang, T., Zhang, J. B., Qu, B., and Liao, Y. C. 2015. Hostinduced gene silencing of an essential chitin synthase gene confers durable resistance to Fusarium head blight and seedling blight in wheat. Plant Biotechnol. J. 13:1335-1345.

Cooper, B. 2014. Proof by synthesis of Tobacco mosaic virus. Genome Biol. 15:R67.

Cooper, B., Campbell, K. B., Beard, H. S., Garrett, W. M., and Islam, N. 2016. Putative rust fungal effector proteins in infected bean and soybean leaves. Phytopathology 106:491-499.

Cooper, B., Campbell, K. B., McMahon, M. B., and Luster, D. G. 2013. Disruption of Rppl-mediated soybean rust immunity by virus-induced gene silencing. Plant Signal. Behav. 8:e27543.

Cooper, B., Neelam, A., Campbell, K. B., Lee, J., Liu, G., Garrett, W. M., Scheffler, B., and Tucker, M. L. 2007. Protein accumulation in the germinating Uromyces appendiculatus uredospore. Mol. Plant-Microbe Interact. 20:857-866.

Dalakouras, A., Wassenegger, M., McMillan, J. N., Cardoza, V., Maegele, I., Dadami, E., Runne, M., and Krczal, G. 2016. Induction of silencing in plants by high-pressure spraying of in vitro-synthesized small RNAs. Front. Plant Sci. 7:1327.

De Carvalho, M. C., Nascimento, L. C., Darben, L. M., Polizel-Podanosqui, A. M., Lopes-Caitar, V. S., Qi, M., Rocha, C. S., Carazzolle, M. F., Kuwahara, M. K., Pereira, G. A., Abdelnoor, R. V., Whitham, S. A., and Marcelino-Guimaraes, F. C. 2016. Prediction of the in planta P. pachyrhizi secretome and potential effector families. Mol. Plant Pathol. 18:363-377.

Dodds, P. N., Lawrence, G. J., Catanzariti, A. M., Ayliffe, M. A., and Ellis, J. G. 2004. The Melampsora lini AvrL567 avirulence genes are expressed in haustoria and their products are recognized inside plant cells. Plant Cell 16: 755-768.

Dodds, P. N., Lawrence, G. J., Catanzariti, A. M., Teh, T., Wang, C. I., Ayliffe, M. A., Kobe, B., and Ellis, J. G. 2006. Direct protein interaction underlies gene-for-gene specificity and coevolution of the flax resistance genes and flax rust avirulence genes. Proc. Natl. Acad. Sci. USA 103:8888-8893.

Garnica, D. P., Nemri, A., Upadhyaya, N. M., Rathjen, J. P., and Dodds, P. N. 2014. The ins and outs of rust haustoria. PLoS Pathog. 10:e1004329.
Germain, H., Joly, D. L., Mireault, C., Plourde, M. B., Letanneur, C., Stewart, D., Morency, M. J., Petre, B., Duplessis, S., and Seguin, A. 2017. Infection assays in Arabidopsis reveal candidate effectors from the poplar rust fungus that promote susceptibility to bacteria and oomycete pathogens. Mol. Plant Pathol. doi:10.1111/mpp.12514

Govindarajulu, M., Epstein, L., Wroblewski, T., and Michelmore, R. W. 2015. Host-induced gene silencing inhibits the biotrophic pathogen causing downy mildew of lettuce. Plant Biotechnol. J. 13:875-883.

Hacquard, S., Joly, D. L., Lin, Y. C., Tisserant, E., Feau, N., Delaruelle, C., Legue, V., Kohler, A., Tanguay, P., Petre, B., Frey, P., Van de Peer, Y., Rouze, P., Martin, F., Hamelin, R. C., and Duplessis, S. 2012. A comprehensive analysis of genes encoding small secreted proteins identifies candidate effectors in Melampsora larici-populina (poplar leaf rust). Mol. Plant-Microbe Interact. 25:279-293.

Hoch, H. C., Staples, R. C., Whitehead, B., Comeau, J., and Wolf, E. D. 1987. Signaling for growth orientation and cell differentiation by surface topography in Uromyces. Science 235:1659-1662.

Hu, Z., Parekh, U., Maruta, N., Trusov, Y., and Botella, J. R. 2015. Downregulation of Fusarium oxysporum endogenous genes by host-delivered RNA interference enhances disease resistance. Front. Chem. 3:1.

Huang, J., Yang, M., Lu, L., and Zhang, X. 2016. Diverse functions of small RNAs in different plant-pathogen communications. Front. Microbiol. 7: 1552.

Johnson, T. 1961. Man-guided evolution in plant rusts: Through his modification of the host plants of the cereal rusts, man is also modifying the rusts. Science 133:357-362.

Kemen, E., Kemen, A., Ehlers, A., Voegele, R., and Mendgen, K. 2013. A novel structural effector from rust fungi is capable of fibril formation. Plant J. 75:767-780.

Kemen, E., Kemen, A. C., Rafiqi, M., Hempel, U., Mendgen, K., Hahn, M., and Voegele, R. T. 2005. Identification of a protein from rust fungi transferred from haustoria into infected plant cells. Mol. Plant-Microbe Interact. 18:1130-1139.

Koch, A., Biedenkopf, D., Furch, A., Weber, L., Rossbach, O., Abdellatef, E., Linicus, L., Johannsmeier, J., Jelonek, L., Goesmann, A., Cardoza, V., McMillan, J., Mentzel, T., and Kogel, K. H. 2016. An RNAi-based control of Fusarium graminearum infections through spraying of long dsRNAs involves a plant passage and is controlled by the fungal silencing machinery. PLoS Pathog. 12:e1005901.

Koch, A., Kumar, N., Weber, L., Keller, H., Imani, J., and Kogel, K. H. 2013. Host-induced gene silencing of cytochrome P450 lanosterol C14 $\alpha$ demethylase-encoding genes confers strong resistance to Fusarium species. Proc. Natl. Acad. Sci. USA 110:19324-19329.

Kunjeti, S. G., Iyer, G., Johnson, E., Li, E., Broglie, K. E., Rauscher, G., and Rairdan, G. J. 2016. Identification of Phakopsora pachyrhizi candidate effectors with virulence activity in a distantly related pathosystem. Front. Plant Sci. 7:269.

Lee, J., Feng, J., Campbell, K. B., Scheffler, B. E., Garrett, W. M., Thibivilliers, S., Stacey, G., Naiman, D. Q., Tucker, M. L., Pastor-Corrales, M. A., and Cooper, B. 2009. Quantitative proteomic analysis of bean plants infected by a virulent and avirulent obligate rust fungus. Mol. Cell. Proteomics 8:19-31.

Link, T. I., Lang, P., Scheffler, B. E., Duke, M. V., Graham, M. A., Cooper, B., Tucker, M. L., van de Mortel, M., Voegele, R. T., Mendgen, K., Baum, T. J., and Whitham, S. A. 2014. The haustorial transcriptomes of Uromyces appendiculatus and Phakopsora pachyrhizi and their candidate effector families. Mol. Plant Pathol. 15:379-393.

Liu, C., Pedersen, C., Schultz-Larsen, T., Aguilar, G. B., Madriz-Ordenana, K., Hovmoller, M. S., and Thordal-Christensen, H. The stripe rust fungal effector PEC6 suppresses pattern-triggered immunity in a host speciesindependent manner and interacts with adenosine kinases. New Phytol. In press. doi:10.1111/nph.14034

Muller, L. V., Rijkenberg, F. H. T., and Truter, S. J. 1974. Ultrastructure of the uredial stage of Uromyces appendiculatus. Phytophylactica 6:73-104.

Niks, R. E., Qi, X., and Marcel, T. C. 2015. Quantitative resistance to biotrophic filamentous plant pathogens: Concepts, misconceptions, and mechanisms. Annu. Rev. Phytopathol. 53:445-470.

Nowara, D., Gay, A., Lacomme, C., Shaw, J., Ridout, C., Douchkov, D., Hensel, G., Kumlehn, J., and Schweizer, P. 2010. HIGS: Host-induced gene silencing in the obligate biotrophic fungal pathogen Blumeria graminis. Plant Cell 22:3130-3141.

Nunes, C. C., and Dean, R. A. 2012. Host-induced gene silencing: A tool for understanding fungal host interaction and for developing novel disease control strategies. Mol. Plant Pathol. 13:519-529.

Panwar, V., McCallum, B., and Bakkeren, G. 2013. Host-induced gene silencing of wheat leaf rust fungus Puccinia triticina pathogenicity genes mediated by the Barley stripe mosaic virus. Plant Mol. Biol. 81:595-608.

Pastor-Corrales, M. A. 2004. Review of coevolution studies between pathogens and their common bean hosts: Implication for the development of disease-resistant beans. Annu. Rep. Bean Improv. Coop. 47:67-68. 
Pastor-Corrales, M. A., Stavely, J. R., Kelly, J. D., Grafton, K. F., Steadman, J. R., Coyne, D. P., Lindgren, D. T., and Scully, B. T. 2001. Rust and mosaic resistant bean germplasm releases, 1997-1999. Annu. Rep. Bean Improv. Coop. 44:101-102.

Petre, B., Saunders, D. G., Sklenar, J., Lorrain, C., Win, J., Duplessis, S., and Kamoun, S. 2015. Candidate effector proteins of the rust pathogen $\mathrm{Mel}$ ampsora larici-populina target diverse plant cell compartments. Mol. PlantMicrobe Interact. 28:689-700.

Petry, N., Boy, E., Wirth, J. P., and Hurrell, R. F. 2015. Review: The potential of the common bean (Phaseolus vulgaris) as a vehicle for iron biofortification. Nutrients 7:1144-1173.

Pretsch, K., Kemen, A., Kemen, E., Geiger, M., Mendgen, K., and Voegele, R. 2013. The rust transferred proteins-A new family of effector proteins exhibiting protease inhibitor function. Mol. Plant Pathol. 14:96-107.

Puthoff, D. P., Neelam, A., Ehrenfried, M. L., Scheffler, B. E., Ballard, L., Song, Q., Campbell, K. B., Cooper, B., and Tucker, M. L. 2008. Analysis of expressed sequence tags from Uromyces appendiculatus hyphae and haustoria and their comparison to sequences from other rust fungi. Phytopathology 98:1126-1135.

Qi, M., Link, T. I., Muller, M., Hirschburger, D., Pudake, R. N., Pedley, K. F., Braun, E., Voegele, R. T., Baum, T. J., and Whitham, S. A. 2016. A small cysteine-rich protein from the Asian soybean rust fungus, Phakopsora pachyrhizi, suppresses plant immunity. PLoS Pathog. 12:e1005827.

Ramachandran, S. R., Yin, C., Kud, J., Tanaka, K., Mahoney, A. K., Xiao, F., and Hulbert, S. H. 2017. Effectors from wheat rust fungi suppress multiple plant defense responses. Phytopathology 107:75-83.

Schmutz, J., McClean, P. E., Mamidi, S., Wu, G. A., Cannon, S. B., Grimwood, J., Jenkins, J., Shu, S., Song, Q., Chavarro, C., Torres-Torres, M., Geffroy, V., Moghaddam, S. M., Gao, D., Abernathy, B., Barry, K., Blair, M., Brick, M. A., Chovatia, M., Gepts, P., Goodstein, D. M., Gonzales, M., Hellsten, U., Hyten, D. L., Jia, G., Kelly, J. D., Kudrna, D., Lee, R., Richard, M. M., Miklas, P. N., Osorno, J. M., Rodrigues, J., Thareau, V., Urrea, C. A., Wang, M., Yu, Y., Zhang, M., Wing, R. A., Cregan, P. B., Rokhsar, D. S., and
Jackson, S. A. 2014. A reference genome for common bean and genomewide analysis of dual domestications. Nat. Genet. 46:707-713.

Staples, R. C., and Hoch, H. C. 1988. Preinfection changes in germlings of a rust fungus induced by host contact. Pages 82-93 in: Biotechnology for Crop Protection. P. A. Hedin, J. J. Menn, and R. M. Hollingworth, eds. American Chemical Society, Washington, DC.

Suzuki, N., Kudo, T., Shirako, Y., Ehara, Y., and Tachibana, T. 1989. Distribution of cylindrical inclusion, amorphous inclusion, and capsid proteins of watermelon mosaic virus 2 in systemically infected pumpkin leaves. J. Gen. Virol. 70:1085-1091.

Tinoco, M. L., Dias, B. B., Dall'Astta, R. C., Pamphile, J. A., and Aragao, F. J. 2010. In vivo trans-specific gene silencing in fungal cells by in planta expression of a double-stranded RNA. BMC Biol. 8:27.

Voegele, R. T., Struck, C., Hahn, M., and Mendgen, K. 2001. The role of haustoria in sugar supply during infection of broad bean by the rust fungus Uromyces fabae. Proc. Natl. Acad. Sci. USA 98:8133-8138.

Yarwood, C. E. 1951. Associations of rust and virus infections. Science 114: 127-128.

Yin, C., Downey, S. I., Klages-Mundt, N. L., Ramachandran, S., Chen, X., Szabo, L. J., Pumphrey, M., and Hulbert, S. H. 2015. Identification of promising host-induced silencing targets among genes preferentially transcribed in haustoria of Puccinia. BMC Genomics 16:579.

Yin, C., Jurgenson, J. E., and Hulbert, S. H. 2011. Development of a hostinduced RNAi system in the wheat stripe rust fungus Puccinia striiformis f. sp. tritici. Mol. Plant-Microbe Interact. 24:554-561.

Zhang, C., Bradshaw, J. D., Whitham, S. A., and Hill, J. H. 2010. The development of an efficient multipurpose bean pod mottle virus viral vector set for foreign gene expression and RNA silencing. Plant Physiol. 153:52-65.

Zhang, C., Whitham, S. A., and Hill, J. H. 2013. Virus-induced gene silencing in soybean and common bean. Methods Mol. Biol. 975:149-156.

Zhang, C., Yang, C., Whitham, S. A., and Hill, J. H. 2009. Development and use of an efficient DNA-based viral gene silencing vector for soybean. Mol. Plant-Microbe Interact. 22:123-131. 